\title{
Atendimento psicológico ao PaCiente Cirúrgico: CONTRIBUiÇÕES PSICANALÍTICAS AO trabalho no Hospital Geral
}

\author{
Renata Sales Martins, Bruna de \\ Oliveira Santos Pinto, Cristiane de Figueiredo Costa, ${ }^{\star}$ \\ Paulo Roberto Mattos da Silva, ${ }^{\star \star}$ \\ e José Henrique Valentim ${ }^{\star \star \star}$
}

Palavras-chave: Psicanálise. Hospital Geral. Atendimento Psicológico.

INTRODUÇão: Este trabalho foi elaborado no âmbito do projeto permanente de extensão "Serviço de Psicologia da Área Cirúrgica - GSI/HUAP" (atendimento psicológico a pacientes cirúrgicos), desenvolvido, de forma ininterrupta, desde 1987, sob a coordenação dos professores Paulo R. Mattos e José Henrique Valentim, tendo a perspectiva de integrar numa matriz de trabalho extensionista as dimensões de ensino, na esfera tanto da graduação quanto da pós-graduação, e a pesquisa de forma continuada. O projeto também visa analisar a contribuição psicanalítica ao trabalho em HG, na consecução de parâmetros específicos.

OвJEtivos: Pesquisar limites e possibilidades da clínica psicanalítica no âmbito do hospital geral; utilizar ferramentas psicanalíticas no atendimento de pacientes internados em hospital geral; pesquisar os elementos clínicos passíveis de serem utilizados em um contexto diferente daquele em relação ao qual a própria psicanálise se constituiu; investigar aspectos passíveis de gerar novas potencializações do dispositivo analítico.

Metodologia: Estudo de textos psicanalíticos, atendimento a pacientes, discussão de casos, elaboração de estratégias de intervenção em bases psicanalíticas.

RESUltados: Utilização de ferramentas psicanalíticas no atendimento a pacientes internados no HUAP, capacitação de alunos de psicologia no atendimento em hospital geral em bases psicanalíticas, contribuições teórico-clínicas ao trabalho psicanalítico em instituições de saúde.

* Estagiários do SPAC e alunos do Curso de Graduação em Psicologia da UFF.

$\star \star$ Professor adjunto do Departamento de Psicologia da UFF e coordenador do SPAC.

$\star \star \star$ Professor adjunto do Departamento de Psicologia da UFF e coordenador do SPAC. Endereço: Av. Visconde do Rio Branco, s/nº, Campus do Gragoatá, Bloco O, sala 310, São Domingos, Niterói, RJ, Tel.: (21) 2629-5018.

E-mail: valentim@vm.uff.br 